HEAD AND NECK

\title{
Clinicopathologic idiosyncrasies of nasopharyngeal cancer in a moderate-risk Mediterranean region
}

\author{
Caratteristiche clinicopatologiche del carcinoma rinofaringeo in una regione \\ dell'area mediterranea a rischio moderato
}

\author{
K. KOURELIS ${ }^{1}$, T. STERGIOU², A. PAPADAS ${ }^{2}$, T. KOURELIS ${ }^{3}$, E. PETTA ${ }^{4}$, T. PAPADAS ${ }^{2}$ \\ ${ }^{1}$ Department of Otorhinolaryngology, Children's General Hospital "Karamandaneio", Patras, Greece; ${ }^{2}$ Department \\ of Otorhinolaryngology, University Hospital of Patras, Patras, Greece; ${ }^{3}$ Department of Medical Oncology, \\ "Olympion" General Hospital, Patras, Greece; ${ }^{4}$ Paliative Care Unit Galilee, Athens, Greece
}

\begin{abstract}
SUMMARY
Cancer of the nasopharynx displays an unparalleled skewness of its epidemiologic, pathogenic and clinico-prognostic characteristics depending on the geographic location. Between the endemic and sporadic forms, which occur in Southeastern Asia and Northern America, respectively, intermediate incidence is noted around the Mediterranean. This study describes the patterns of the disease affecting the population of Western Greece. The records of 70 patients with nasopharyngeal cancer diagnosed in a single institution between 1994-2014 were retrospectively reviewed. Primary treatment involved irradiation with or without concurrent chemotherapy. Demographic data, patient risk factors, tumour parameters, clinical presentation and treatment outcomes were assessed for potential intercorrelations. Overall (OS) and disease-specific (DSS) 5-year survival rates were determined. Possible predictors of survival were tested on univariate and multivariate analysis. WHO-type 3 histopathology was diagnosed predominantly $(74.3 \%)$ and associated significantly with nasal symptomatology upon presentation $(p=0.050)$, metastatic lymphadenopathy $(p=0.028)$, advanced clinical stage $(p=0.009)$ and complete response to initial treatment $(\mathrm{p}=0.018)$. Univariate analysis revealed a negative prognostic significance for older age (OS, $p=0.029 \mathrm{DSS}, \mathrm{p}=0.041)$, poor response to treatment (OS \& DSS p < 0.001) and cancer recurrence (OS, p = 0.003 DSS, p $=0.001)$. On multivariate analysis, disease relapse maintained its adverse effect (HR 7.442, 95\% CI 2.199-25.187, p = 0.001). In conclusion, among nasopharyngeal carcinomas arising in western Greece, lymphoepitheliomas manifest a distinct clinical behaviour, so that their latest grouping along with WHO-type 2 tumours into the "non-keratinising" category may not apply. Regardless of pathology, cancer recurrence after initial remission is a severe event.
\end{abstract}

KEY WORDS: Epidemiology $\bullet$ Nasopharyngeal neoplasms $\bullet$ Pathology $\bullet$ Prognosis

\section{RIASSUNTO}

Il carcinoma del rinofaringe presenta una notevole eterogeneità per quanto riguarda le caratteristiche epidemiologiche, patogenetiche, cliniche e prognostiche sulla base dell'area geografica considerata. L'incidenza registrata nel Mediterraneo per tale patologia si colloca fra quella delle forme epidemiche e sporadiche registrate rispettivamente nel Sud Est Asiatico e nel Nord America. Il presente studio descrive le caratteristiche di questa patologia per quanto riguarda l'ovest della Grecia. Sono stati analizzati i dati relativi a 70 pazienti affetti da carcinoma del rinofaringe la cui diagnosi è stata posta presso un singolo centro fra il 1994 e il 2014. Il trattamento primario si è basato sulla radioterapia con o senza chemioterapia associata. Sono stati raccolti ai fini dell'analisi statistica i dati demografici, i fattori di rischio, le caratteristiche della neoplasia, la presentazione clinica e l'outcome. Sono state calcolate sia la sopravvivenza globale (OS) che la sopravvivenza specifica per malattia (DSS) a 5 anni. Tutti i fattori potenzialmente predittori di sopravvivenza sono stati testati a un'analisi univariata e multivariata. La variante maggiormente diagnosticata all'analisi istopatologica è stato il tipo 3 secondo la WHO $(74,3 \%)$ che si è associato in modo significativo con sintomatologia nasale alla presentazione $(p=0,050)$, linfoadenopatie metastatiche $(p=0,028)$, stage clinico avanzato $(p=0,009)$ e risposta completa al trattamento iniziale $(p=0,018)$. L'analisi univariata ha evidenziato un impatto negativo in termini prognostici per l'età avanzata (OS $p=0,029, D S S p=0,041)$, la mancata risposta ai trattamenti (OS \& DSS $p<0,001)$ e la recidiva di malattia (OS $p=0,003$, DSS $p=0,001)$. A un'analisi multivariata la recidiva di malattia ha mantenuto un impatto prognostico negativo (HR 7,442, 95\% IC 2,199-25,187, $p=0,001)$. In conclusione, fra i carcinomi nasofaringei diagnosticati nell'ovest della Grecia, il linfoepitelioma mostra caratteristiche peculiari sotto il profilo clinico, tali per cui la sua inclusione assieme alle neoplasie tipo 2 secondo la WHO nel gruppo di carcinomi rinofaringei "non cheratinizzanti" potrebbe risultare inappropriata. Infine, la recidiva di malattia, indipendentemente dagli altri fattori in gioco, appare essere un evento gravemente avverso.

PAROLE CHIAVE: Epidemiologia $\bullet$ Neoplasie del rinofaringe $\bullet$ Patologia $\bullet$ Prognosi

Acta Otorhinolaryngol Ital 2017;37:180-187 


\section{Introduction}

Of all head and neck epithelial malignancies, nasopharyngeal cancer historically holds a unique position, being different essentially in every aspect of its clinic-biologic profile. Tumours of the nasopharynx share the privilege of silent growth, as they expand inside a hidden cavity and do not impinge on nerves unless substantial enlargement has occurred. Not only that, but due to its core location, this head and neck region is not amenable to radical surgery ${ }^{1}$. Notably, the micro-anatomy of the area is as distinct as its macro-anatomy: the nasopharyngeal lumen is lined with transitional epithelium, instead of the stratified squamous cell layer which gives rise to more than $90 \%$ of head and neck carcinomas. Moreover, subepithelial tissues are heavily infiltrated with lymphocytes. Collectively, such a histological arrangement explains the diversity of tumour pathology originating in the same area. For the last four decades, nasopharyngeal carcinomas have been traditionally grouped into three types: (a)-WHO type 1, identical to the common form of keratinising head and neck squamous cell carcinoma, (b)-WHO type 2 , the poorly differentiated, non-keratinising squamous cell variant, and (c)-WHO type 3, a.k.a. lymphoepithelioma, which lacks any cellular differentiation ${ }^{2}$. The heterogeneity in histopathology reflects the variety of clinical patterns, that is, WHO type 1 neoplasms predominate in the older population and tend to advance locally, whereas WHO types 2 and 3 carry a higher risk of distant spread. Lymphoepitheliomas in particular, though histologically undifferentiated and frequently metastatic, present with the paradox of a more favourable prognosis, owing to their enhanced radio- and chemo-sensitivity ${ }^{3}$.

As is the case in virtually all kinds of malignancy, the aetiology of nasopharyngeal cancer is multifactorial. Genetic predisposition, dietary carcinogens, smoking, occupational exposure and latent Epstein-Barr virus (EBV) infection have all been implicated, if not documented. Interestingly, it seems that each WHO histological type is associated with a distinct pathogenesis and combination of inducing factors. In detail, WHO type 1 carcinomas demonstrate a robust correlation with alcohol and tobacco, in resemblance with the classic head and neck cancer, while types 2 and 3 share a stronger relationship with EBV infection ${ }^{4}$.

The histologic, clinical and aetiologic diversity of epithelial nasopharyngeal tumours is not distributed uniformly around the globe, but exhibits geographic differences. In that regard, cancers of the nasopharynx belong to an enigmatic group of neoplasias such as Kaposi's sarcoma and Burkitt's lymphoma, which occur either in a sporadic or endemic form in specific regions of the planet, maintaining a clear-cut distinction between the clinico-pathophysiologic features of the two disease types. The "en- demic" areas of nasopharyngeal cancer extend across most of Southeastern Asia, where at specific locations, e.g. Hong Kong, the incidence is 30 times higher than that observed in the "sporadic" regions, typically USA and Western Europe. Focusing on Europe, the incidence across the Mediterranean countries (1.4 cases/100,000 men), including Greece, is higher than the northern part $(<1 / 100,000)^{5}$. As stated above, the endemic and sporadic forms differ in terms of pathogenesis and clinical aggression. Roughly speaking, tumours of WHO 3 and 2 histological class are associated with the former type, whereas the keratinising carcinomas tend to occur in the sporadic fashion ${ }^{2}$. However, there is little knowledge of the clinicopathologic profile of nasopharyngeal cancer diagnosed in "grey" regions, such as Mediterranean countries. In an attempt to fill in a piece of the geographic puzzle, this study aims to record the individual characteristics of the disease affecting the population of Western Greece.

\section{Materials and methods}

This retrospective study was approved by our institution's Research Ethics Committee. Patras University hospital receives the majority of cancer patients from Western Greece, with a population of 2,500,000. The records of 70 consecutive nasopharyngeal cancer patients diagnosed from 1994 to 2014 were reviewed. For all cases, diagnostic work-up, histologic confirmation and treatment were provided in our institution. Social history was also documented. Smokers' classification was based on the number of pack years, as moderate $(\leq 20)$ or heavy (>20). Alcohol drinking was graded as social (up to three drinks/week), moderate (3-7 drinks) and heavy (> 7 drinks). The management plan entailed conventional irradiation of the primary tumour with a total dose of $6600-7000 \mathrm{cGy}$, along with therapeutic (6600-7000 cGy) or prophylactic (5000 cGy) targeting of the neck. Concurrent chemotherapy with cis-platinum and 5-fluouracil was offered to patients of stage II or higher. A salvage neck dissection was performed in case of regional recurrence. Patients were followed-up every 2 months for the first post-treatment year, every 3 months for the next two years, twice annually for the 4th and 5th years and yearly afterwards. The follow-up period stretched between 1 and 176 months. Complete clinical response was defined as the documentation of pure scarred tissue along the nasopharyngeal walls, without evidence of deep invasion, or regional or distant disease. Patients with complete response and new evidence of disease at least 6 months after completion of treatment were classified as recurrences. Because relapsing patients would often seek a second opinion before showing to follow-up in our institution, unfortunately our data regarding the exact time and sort of recurrence were scant, and thus omitted from 
subsequent processing. The collected information included demographics, initial manifestation, TNM classification, histology, response to treatment, tumour recurrence within 3 years from the completion of treatment and are summarised in Table I.

The correlations between categorical values were investigated by either Chi-square or Fisher's exact test. The Kaplan-Meier method produced all survival analyses, and the log-rank test was employed to determine the statistical significance of differences among the survival rates of various patient subgroups. To eliminate censoring, living patients with duration of follow-up shorter than 60 months were not considered for calculation of 5 -year cumulative survival. Prognostic factors exhibiting a $p$ value $<0.2$ on univariate testing, were next submitted to a multivariate Cox-regression model to assess their independent influence. A two-sided $p$ value $\leq 0.05$ was considered significant. All tests were performed using SPSS 17.0 statistical software.

\section{Results}

Chi-square, or Fisher's exact test in the case of binomial variables, were utilised to determine the effect of our sample's demographics, smoking and alcohol consumption data on tumour characteristics, as well as on clinical course. None of the correlations produced statistically significant results. In the second set of analyses, the association of the WHO histologic type with the locoregional and distant extent of disease was explored. We also examined the impact of histopathology and TNM classification on the original manifestation and the pattern of clinical progression, the latter defined by the responsiveness to initial treatment and the risk of recurrence. At first, we failed to establish any statistically significant differences among the clinicoprognostic variables of the three WHO histologic subgroups. It is likely that the small number of WHO type 1 carcinomas limited the statistical power of the analyses. Next, we merged cases with WHO types 1 and 2 into a single group, the so-called "squamous cell differentiated" type, as opposed to the undifferentiated WHO type 3. Furthermore, aiming to focus exclusively on those cases presenting with local symptomatology as the primary manifestation, we investigated only patients complaining initially either of hearing loss or of a nasal symptom, i.e. epistaxis or nasal obstruction.

Subsequent to our data regrouping, Chi-square testing yielded several significant relationships (Table II). To begin with, WHO type 3 histology was significantly associated with an increased rate of neck metastases at diagnosis. Of note, $80.8 \%$ (42/52) of lymphoepitheliomas manifested regional spread, whereas in only half $(9 / 18)$ of WHO type 1 and 2 carcinomas was lymph node involvement detected. No relationship could be established between the state of differentiation and $\mathrm{N}$ staging,
Table I. Characteristics of the study population.

\begin{tabular}{|c|c|c|}
\hline Description & $\mathrm{N}$ & $\%$ \\
\hline \multicolumn{3}{|l|}{ Gender } \\
\hline Male & 54 & 77.1 \\
\hline Female & 16 & 22.9 \\
\hline \multicolumn{3}{|l|}{ Age } \\
\hline Mean (range) & $56.3(16-85)$ & \\
\hline \multicolumn{3}{|l|}{ Smoking } \\
\hline No & 26 & 37.2 \\
\hline Moderate & 8 & 11.4 \\
\hline Heavy & 36 & 51.4 \\
\hline \multicolumn{3}{|l|}{ Alcohol } \\
\hline No & 40 & 57.1 \\
\hline Social & 11 & 15.7 \\
\hline Moderate & 10 & 14.3 \\
\hline Heavy & 9 & 12.9 \\
\hline \multicolumn{3}{|l|}{ Initial manifestation } \\
\hline Otitis media with effusion & 15 & 21.4 \\
\hline Epistaxis & 12 & 17.1 \\
\hline Nasal obstruction & 3 & 4.3 \\
\hline Facial numbness/pain & 2 & 2.9 \\
\hline Neck mass & 38 & 54.3 \\
\hline \multicolumn{3}{|l|}{ WHO histologic type } \\
\hline I & 3 & 4.3 \\
\hline$\|$ & 15 & 21.4 \\
\hline III & 52 & 74.3 \\
\hline \multicolumn{3}{|l|}{$\mathrm{T}$} \\
\hline 1 & 57 & 81.4 \\
\hline 2 & 10 & 14.3 \\
\hline 4 & 3 & 4.3 \\
\hline \multicolumn{3}{|l|}{ N } \\
\hline 0 & 19 & 27.1 \\
\hline 1 & 7 & 10.0 \\
\hline 2 & 31 & 44.3 \\
\hline 3 & 13 & 18.6 \\
\hline \multicolumn{3}{|l|}{ M } \\
\hline 0 & 69 & 98.6 \\
\hline 1 & 1 & 1.4 \\
\hline \multicolumn{3}{|l|}{ Stage } \\
\hline I & 17 & 24.3 \\
\hline$\|$ & 7 & 10.0 \\
\hline III & 29 & 41.4 \\
\hline IV & 17 & 24.2 \\
\hline \multicolumn{3}{|l|}{ Radiation } \\
\hline Yes & 70 & 100 \\
\hline No & 0 & 0 \\
\hline \multicolumn{3}{|l|}{ Chemotherapy } \\
\hline Yes & 22 & 31.4 \\
\hline No & 48 & 68.6 \\
\hline \multicolumn{3}{|l|}{ Neck dissection } \\
\hline Yes & 7 & 10.0 \\
\hline No & 63 & 90.0 \\
\hline \multicolumn{3}{|l|}{ Complete response } \\
\hline Yes & 63 & 90.0 \\
\hline No & 3 & 4.3 \\
\hline No available data & 4 & 5.7 \\
\hline \multicolumn{3}{|l|}{ Recurrence } \\
\hline Yes & 21 & 33.3 \\
\hline No & 36 & 57.1 \\
\hline No available data & 6 & 9.6 \\
\hline
\end{tabular}


Table II. Comparison between the differentiated and undifferentiated nasopharyngeal cancer subgroups.

\begin{tabular}{|c|c|c|c|}
\hline \multirow{2}{*}{ Patient variable } & \multicolumn{2}{|c|}{$\mathrm{N}(\%)$} & \multirow[t]{2}{*}{$P$} \\
\hline & WHO 1 and 2 & WHO 3 & \\
\hline Gender & & & 0.536 \\
\hline Male & $13(24.1)$ & $41(75.9)$ & \\
\hline Female & $5(31.3)$ & $11(68.8)$ & \\
\hline Age & & & 0.259 \\
\hline$\leq 50$ & $4(16.7)$ & 20 (83.3) & \\
\hline$>50$ & $14(30.4)$ & $32(69.6)$ & \\
\hline Smoking & & & 0.540 \\
\hline No & $5(19.2)$ & 21 (80.8) & \\
\hline Moderate & $3(37.5)$ & 5 (62.5) & \\
\hline Heavy & $10(27.8)$ & $26(72.2)$ & \\
\hline Alcohol & & & 0.958 \\
\hline No & $11(27.5)$ & $29(72.5)$ & \\
\hline Social & $3(27.3)$ & $8(72.7)$ & \\
\hline Moderate & $2(20.0)$ & $8(80.0)$ & \\
\hline Heavy & $2(22.2)$ & 7 (77.8) & \\
\hline Initial manifestation & & & 0.414 \\
\hline Local & $10(31.3)$ & $22(68.8)$ & \\
\hline Neck mass & $8(21.1)$ & 30 (78.9) & \\
\hline Initial local manifestation & & & 0.050 \\
\hline Aural & $8(53.3)$ & $7(46.7)$ & \\
\hline Nasal & $2(13.3)$ & $13(86.7)$ & \\
\hline $\mathrm{T}$ & & & 0.564 \\
\hline 1 & 15 (26.3) & $42(73.7)$ & \\
\hline 2 & $3(30.0)$ & $7(70.0)$ & \\
\hline 4 & 0 & $3(100.0)$ & \\
\hline N & & & 0.028 \\
\hline 0 & $9(47.4)$ & $10(52.6)$ & \\
\hline+ & $9(17.6)$ & $42(82.4)$ & \\
\hline M & & & 1.000 \\
\hline 0 & $18(26.1)$ & $51(73.9)$ & \\
\hline 1 & 0 & $1(100.0)$ & \\
\hline Stage & & & 0.009 \\
\hline$|-| \mid$ & $11(45.8)$ & $13(54.2)$ & \\
\hline III-IV & 7 (15.2) & $39(84.8)$ & \\
\hline Complete response to treatment & & & 0.018 \\
\hline No & $3(100.0)$ & $0(0.0)$ & \\
\hline Yes & $15(23.8)$ & 48 (76.2) & \\
\hline Recurrence & & & 0.059 \\
\hline No & $6(16.7)$ & 30 (83.3) & \\
\hline Yes & $9(42.9)$ & $12(57.1)$ & \\
\hline
\end{tabular}

however. Nonetheless, a clear-cut correlation between advanced clinical stage (III-IV) and WHO type 3 histologic diagnosis was revealed. Moreover, in the subgroup of patients presenting with a local symptom, either aural or nasal, differentiated nasopharyngeal cancer showed a significant relationship with the former [80\% (8/10)], in contrast with the WHO-type 3 neoplasms, which were more likely to cause epistaxis or nasal obstruction [65\% $(13 / 20)]$. Obviously, due to the limited size of this particular subgroup, the above mentioned results need to be approached with caution. With reference to its prognostic significance, undifferentiated cancer manifested absolute response $[100 \%(48 / 48)]$ to initial treatment, while for WHO types 1 and 2 the remission rate was $83.3 \%$ (15/18). Not only, but the recurrence rate after successful response to treatment was lower in WHO type 3 cases $[28.6 \%(12 / 42)]$ than in patients with other pathologies [60\% (9/15)], although the latest association was marginally non-significant.

The overall (OS) and disease-specific (DSS) 5-year survival rates of our patients were $46.9 \%$ and $48.9 \%$, respectively. Univariate comparison of the 5-year OS and DSS curves among the various patient subgroups revealed a negative prognostic significance of older age, poor response to treatment and cancer recurrence. Those parameters, along with neck status and clinical stage, which achieved a $p$ value $<0.2$, were included in the multivariate model. Nevertheless, owing to the limited number of unsuccessful therapies, the treatment response variable was rejected from the final equation. Finally, logistic regression analysis established that in our study population disease recurrence was the sole independent prognostic factor affecting negatively both OS and DSS (Table III). Relapsing patients faced a 7-fold higher risk of dying from nasopharyngeal cancer. Of note, the differentiation state of carcinomas exerted no effect on survival (Fig. 1).

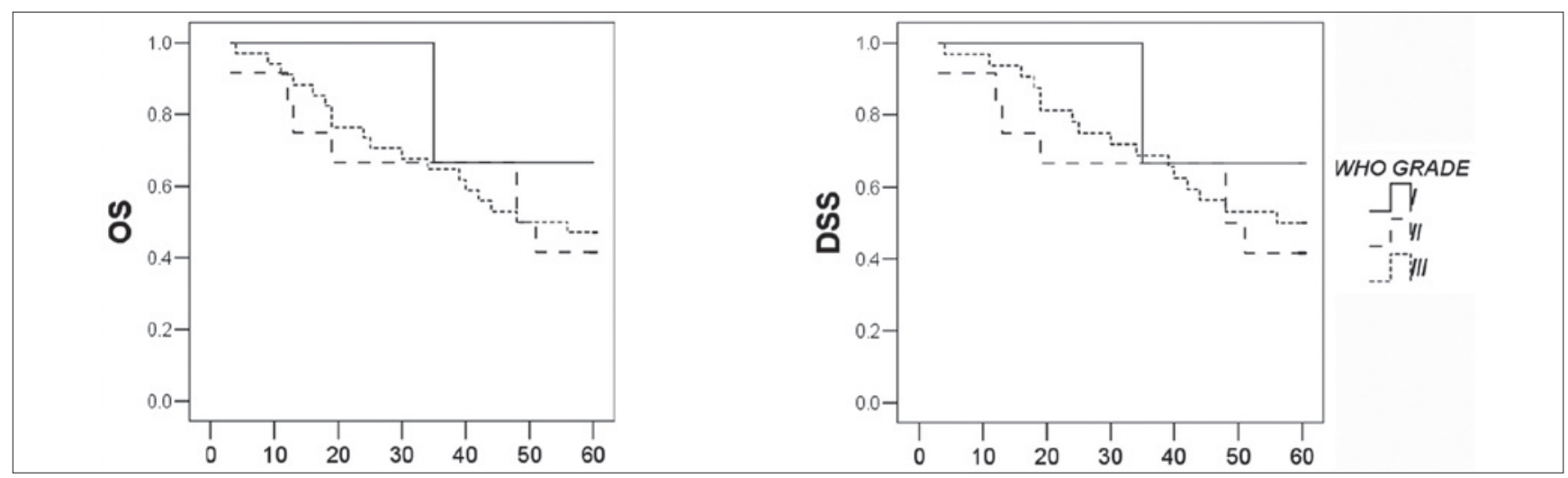

Fig. 1. Kaplan-Meier 5 -year OS $(p=0.770)$ and DSS $(p=0.744)$ survival curves for patients with nasopharyngeal cancer of various histopathological grades. $\mathrm{x}$-axis represents months elapsed since the diagnosis. 
Table III. Univariate and multivariate analyses testing the prognostic effect of various patient and disease parameters on overall and disease-specific 5-year survival.

\begin{tabular}{|c|c|c|c|c|c|c|}
\hline \multirow[t]{3}{*}{ Factor } & \multicolumn{3}{|c|}{ OS } & \multicolumn{3}{|c|}{ DSS } \\
\hline & Univariate & Multivariate & & Univariate & Multivariate & \\
\hline & $P$ & $\mathrm{HR}(95 \% \mathrm{Cl})$ & $P$ & $P$ & $\mathrm{HR}(95 \% \mathrm{Cl})$ & $P$ \\
\hline \multicolumn{7}{|l|}{ Gender } \\
\hline \multicolumn{7}{|l|}{ Male } \\
\hline Female & 0.981 & & & 0.879 & & \\
\hline \multicolumn{7}{|l|}{ Age } \\
\hline$\leq 50$ & & Referent value & & & Referent value & \\
\hline$>50$ & 0.029 & 2.477 (0.707-8.677) & 0.156 & 0.041 & $2.162(0.605-7.773)$ & 0.236 \\
\hline \multicolumn{7}{|l|}{ Smoking } \\
\hline No & & & & & Referent value & \\
\hline Moderate & & & & & $2.785(0.471-16.466)$ & 0.259 \\
\hline Heavy & 0.242 & & & 0.189 & $3.048(0.944-9.845)$ & 0.062 \\
\hline \multicolumn{7}{|l|}{ Alcohol } \\
\hline \multicolumn{7}{|l|}{ No } \\
\hline \multicolumn{7}{|l|}{ Social } \\
\hline \multicolumn{7}{|l|}{ Moderate } \\
\hline Heavy & 0.678 & & & 0.509 & & \\
\hline \multicolumn{7}{|c|}{ Initial manifestation } \\
\hline \multicolumn{7}{|l|}{ Local } \\
\hline Neck mass & 0.970 & & & 0.683 & & \\
\hline \multicolumn{7}{|c|}{ Initial local manifestation } \\
\hline \multicolumn{7}{|c|}{ Aural } \\
\hline Nasal & 0.595 & & & 0.595 & & \\
\hline \multicolumn{7}{|l|}{ WHO type } \\
\hline \multicolumn{7}{|l|}{1 and 2} \\
\hline 3 & 0.949 & & & 0.861 & & \\
\hline \multicolumn{7}{|l|}{$\mathrm{T}$} \\
\hline \multicolumn{7}{|l|}{1} \\
\hline \multicolumn{7}{|l|}{2} \\
\hline 4 & 0.269 & & & 0.261 & & \\
\hline \multicolumn{7}{|l|}{ N } \\
\hline 0 & & Referent value & & & Referent value & \\
\hline+ & 0.076 & $5.470(0.559-53.525)$ & 0.144 & 0.112 & $7.804(0.708-86.050)$ & 0.093 \\
\hline \multirow{2}{*}{\multicolumn{7}{|c|}{ Not enough }} \\
\hline & & & & & & \\
\hline \multicolumn{7}{|c|}{ data } \\
\hline Stage & & & & & & \\
\hline$|-| \mid$ & & Referent value & & & Referent value & \\
\hline III-IV & 0.129 & $1.469(0.220-9.821)$ & 0.692 & 0.190 & $1.305(0.178-9.554)$ & 0.793 \\
\hline Complete resp & & & & & & \\
\hline No & & Rejected & & & Rejected & \\
\hline Yes & $<0.001$ & & & $<0.001$ & & \\
\hline Recurrence & & & & & & \\
\hline No & & Referent value & & & Referent value & \\
\hline Yes & 0.003 & $4.820(1.669-13.915)$ & 0.004 & 0.001 & $7.442(2.199-25.187)$ & 0.001 \\
\hline
\end{tabular}

* $H R$, hazard ratio; $\mathrm{Cl}$, confidence interval.

\section{Discussion}

The epidemiology of nasopharyngeal cancer varies enormously with geographic latitude and longitude, so that it may be unsafe to generalise conclusions pertaining to risk factors, pathogenetic events, or prognostic markers based upon evidence from a single regional tumour registry. Rather, a more comprehensive approach would entail the combination of data from various parts of the world in order to shed light onto the fundamental principles governing the clinical behaviour of such a diverse neoplastic disease. Four decades after the sole publication on the incidence and clinical course of nasopharyngeal cancer in the region of Greece ${ }^{6}$, this study reports the current trends in the local disease pattern. Despite the prolonged accumulation of cases from nearly one-quarter of the Greek population, the size of our study sample, due to the scarce occurrence of nasopharyngeal malignancies, might be still considered insufficient for certain statistical analyses. 
Firstly, the male-to-female ratio $(3: 1)$ and mean age at diagnosis (56 years) of our patient sample were similar to those reported in the literature, both for the sporadic and endemic forms of nasopharyngeal cancer ${ }^{5}$, with the exception of Northern Africa, where a secondary peak incidence is spotted during the second and third decades of life ${ }^{7}$. Apart from that, being an intermediate zone between the sporadic and endemic provinces from a cancer incidence standpoint, Greece also exhibits an average ratio of the histologic subtypes. While in Northern America the $\mathrm{WH}$-types 1, 2 and 3 represent $25 \%, 12 \%$ and $63 \%$, respectively, in the high-risk countries of Southeastern Asia the relative proportions are reported as $2 \%, 3 \%$ and $95 \%$. In our study population, the documented ratio was $4 \%, 22 \%$ and $74 \%$, showing, in comparison with the endemic variant, a rise of the type 2 non-keratinising squamous cell carcinoma, at the expense of lymphoepithelioma. So far, it has been strongly suggested that the nasopharyngeal carcinomas of different histopathologic subtypes correspond to dissimilar pathogenetic processes and predisposing factors. In specific, WHO type 1 tumours share a causal relationship with smoking, as well as a sporadic occurrence, with the classic squamous cell carcinoma arising from the other head and neck subsites, whereas the tumourigenesis of WHO type 3 neoplasms is likely dominated by chronic subclinical EBV infection and thus takes place in the form of an epidemic ${ }^{2}$. Since EBV carrier state is a ubiquitous condition, involving nearly $95 \%$ of the human population, carcinogenic cofactors have been considered in endemic regions, with the primary focus on consumption of salted fish ${ }^{9}$. As the Mediterranean diet does not usually include a substantial amount of preserved fish, our study investigated the role of more "traditional" carcinogenic factors, i.e. smoking and alcohol drinking. None of those demonstrated an association with a distinct WHO type of cancer, although the keratinising tumour was poorly represented in our sample. A multitude of studies from both "hot" and "cold" areas has excluded tobacco and alcohol as risk factors for WHO types 2 and $3^{10}$. Notably, these particular subtypes constitute together $96 \%$ of all our cases, hence suggesting that a different set of carcinogenic factors is possibly responsible for the "Greek variety" of nasopharyngeal cancer. Obviously, the lack of information regarding the presence and severity of EBV-infection in our patients poses a limitation to the conclusions of this study.

The histopathologic identity of nasopharyngeal tumours relates not only to specific aetiopathogenetic factors, but also to distinct clinical patterns. According to our data, a growing neck mass was the commonest symptom that led patients, regardless of histology, to seek medical advice. This finding is in agreement with reports both from sporadic ${ }^{11}$ and endemic ${ }^{12}$ regions. Still, 19\% of our patients, despite having noticeable cervical metastases, did not present for examination until a local mani- festation eventually occurred. It appears that functional compromise, such as hearing loss or nasal obstruction, is more alarming to the patient than a painless lump in the neck. Since the latter unfortunately is a sign of advanced disease, proper education of the population is vital. Among those cases of our study presenting because of a local manifestation, WHO type 3 tumours were associated with nasal symptomatology, either obstruction or epistaxis, in contrast to aural complaints. To date, no relationship has been reported between histological type and initial symptoms. We can only hypothesise that undifferentiated carcinomas, at least during the early stage of their development, tend to grow exophytically into the nasal cavities, whereas the differentiated squamous cell neoplasms exhibit a more lateral, submucosal extension, thus disrupting the function of the eustachian tube ${ }^{13}$. A second finding of our analysis was the increased risk of neck metastases in the lymphoepithelioma subgroup. Due to the higher frequency of regional spread, WHO type 3 tumours of our sample were diagnosed at a relatively advanced clinical stage. Metastatic lymphadenopathy of the neck is a well-established clinical feature of nasopharyngeal cancer of both WHO types 2 and 37 . However, in our regional patient population, we documented a definite distinction between the two histologic variants, i.e., only the undifferentiated carcinomas displayed a clear propensity for lymph node dissemination. Accordingly, advanced clinical stage upon consultation, a hallmark of all forms of nasopharyngeal cancer ${ }^{11}$, was in our study heavily pronounced in WHO type 3 cases, as they most often presented with positive lymph nodes. Certainly the silent tumour growth in such a concealed anatomic location, the vague symptomatology that does not alarm either the patient or even sometimes the physician, as well as the dependence on nasopharyngoscopy to identify the primary lesion, are all contributing factors to considerable disease progression prior to diagnosis ${ }^{14}$. Besides their distinctive tumour parameters, undifferentiated carcinomas included in our study were further distinguished in terms of their response to treatment. Impressively, lymphoepitheliomas responded in toto to the initial therapeutic approach. In addition, they displayed a much lower risk of locoregional or distant recurrence, in comparison with differentiated squamous cell cancer, though this discrepancy was found to be marginally nonsignificant. In the head and neck family of malignancies, cancer of the nasopharynx has traditionally been managed therapeutically by oncologists, instead of surgeons, due to its remarkable radio- and chemo-sensitivity ${ }^{1}$. However, the effect of histopathology on treatment outcome is an issue of controversy. In agreement with our results, more effective disease control for WHO type 3 tumours has been reported in Western populations ${ }^{15}$. Yet in endemic areas, where undifferentiated carcinomas prevail, lymphoepitheliomatous histology is not a clear-cut 
determinant of treatment success, though it confers a survival benefit ${ }^{16}$, even if not evident in our study.

On the basis of our univariate survival analysis, older age, non-response to treatment and cancer recurrence were found to be ominous predictors, although only disease relapse was demonstrated in multivariate testing as an independent adverse indicator. The overall 5-year survival rate in our study $(46.9 \%)$ is within the globally reported range (32-62\%) ${ }^{17}$. However, the survival determinants vary remarkably throughout the literature, reflecting the geographic heterogeneity of the disease. Negative prognostic factors well-established worldwide include older age, advanced TNM stage, cranial nerve involvement and skull-base erosion ${ }^{15} 18$. Excluding distant metastasis, which was diagnosed in only one case on initial evaluation, tumour size and status of the cervical lymph nodes had no impact on survival in our patient group, suggesting that cancer aggressiveness may not be associated with the locoregional extent of disease, as for other carcinomas of the head and neck. Paradoxically, the histologic identity of nasopharyngeal neoplasia, which, as supported by our data, exerted an influence on several clinical parameters, did not produce, as would be expected, an effect on survival, possibly indicating that the entire clinicopathologic cancer profile might not be a reliable marker of the course of disease. Failure to produce a long-term therapeutic outcome was, in our sample, the critical factor that shortened survival. For that reason, highly aggressive but infrequently implemented therapeutic techniques such as intracavitary brachytherapy ${ }^{19}$ and surgical resection ${ }^{7}$ might be applied on a larger scale, particularly in cases of strictly localised recurrent tumours. Not only, but newer treatment modalities, namely intensity-modulated radiation therapy, adjuvant or neo-adjuvant chemotherapy, as well as up-to-date targeted molecular approaches against epidermal growth factor receptor or vascular endothelial growth factor, may be of enormous benefit to nasopharyngeal cancer patients ${ }^{1}$. Admittedly, recurrences in our institution were managed exclusively with salvage neck dissection, when this was applicable, to control of regional spread only. The role of re-irradiation to the primary site merits careful investigation ${ }^{20}$.

\section{Conclusions}

On the whole, the present report documents the epidemiologic and clinicoprognostic traits of nasopharyngeal cancer in Western Greece, an area with intermediate incidence between the endemic and sporadic regions. Perhaps in the era of proteomics and cell signaling modification, purely observational studies might seem outdated. Nevertheless, the comprehensive understanding of a malignancy with such striking differences across the globe requires a piece-by-piece description of its geography. Our findings support a distinct place for WHO type 3 tu- mours, comparatively to the squamous cell group comprising WHO types 1 and 2 together. Accordingly, the categorisation of carcinomas into "undifferentiated" vs. "differentiated" may apply more precisely to our regional variant of the disease, rather than the latest classification by WHO into "non-keratinising"(WHO types 2 and 3) vs. "keratinising"(WHO type 1), proposed in $2005^{21}$. Further exploration of the clinicopathologic diversity of this unpredictable neoplasia might hopefully lead to an accurate universal classification scheme that could facilitate the study of the natural history of the disease and the design of improved treatment strategies.

\section{References}

1 Lee AW, Lin JC, Ng WT. Current management of nasopharyngeal cancer. Semin Radiat Oncol 2012;22:233-44.

2 Vokes EE, Liebowitz DN, Weichselbaum RR. Nasopharyngeal carcinoma. Lancet 1997;350:1087-91.

3 Baker SR. Nasopharyngeal carcinoma: clinical course and results of therapy. Head Neck Surg 1980;3:8-14.

4 Tsao SW, Yip YL, Tsang CM, et al. Etiological factors of nasopharyngeal carcinoma. Oral Oncol 2014;50:330-8.

5 Cancer incidence in five continents. Volume IX. IARC Sci Publ; 2008. p. 1-837.

6 Papavasiliou CG. Cancer of the nasopharynx. Incidence, clinical course and results of therapy: a report from Greece. Clin Radiol 1974;25:409-14.

7 Spano JP, Busson P, Atlan D, et al. Nasopharyngeal carcinomas: an update. Eur J Cancer 2003;39:2121-35.

8 Nicholls JM. Nasopharyngeal carcinoma: classification and histological appearances. Adv Anat Pathol 1997;4:71-84.

9 Yu MC, Garabrant DH, Huang TB, et al. Occupational and other non-dietary risk factors for nasopharyngeal carcinoma in Guangzhou, China. Int J Cancer 1990;45:1033-9.

10 Jia WH, Qin HD. Non-viral environmental risk factors for nasopharyngeal carcinoma: a systematic review. Semin Cancer Biol 2012;22:117-26.

11 Colaco RJ, Betts G, Donne A, et al. Nasopharyngeal carcinoma: a retrospective review of demographics, treatment and patient outcome in a single centre. Clin Oncol ( R Coll Radiol) 2013;25:171-7.

12 Suzina SA, Hamzah M. Clinical presentation of patients with nasopharyngeal carcinoma. Med J Malaysia 2003;58:539-45.

13 Dubrulle F, Souillard R, Hermans R. Extension patterns of nasopharyngeal carcinoma. Eur Radiol 2007;17:2622-30.

14 Skinner DW, Van Hasselt CA, Tsao SY. Nasopharyngeal carcinoma: modes of presentation. Ann Otol Rhinol Laryngol 1991;100:544-51.

15 Sanguineti G, Geara FB, Garden AS, et al. Carcinoma of the nasopharynx treated by radiotherapy alone: determinants of local and regional control. Int J Radiat Oncol Biol Phys 1997;37:985-96.

${ }^{16}$ Liu MT, Hsieh CY, Chang TH, et al. Prognostic factors affecting the outcome of nasopharyngeal carcinoma. Jpn J Clin Oncol 2003;33:501-8. 
17 Farias TP, Dias FL, Lima RA, et al. Prognostic factors and outcome for nasopharyngeal carcinoma. Arch Otolaryngol Head Neck Surg 2003;129:794-9.

18 Heng DM, Wee J, Fong KW, et al. Prognostic factors in 677 patients in Singapore with nondisseminated nasopharyngeal carcinoma. Cancer 1999;86:1912-20.

19 Wang CC. Improved local control of nasopharyngeal carcinoma after intracavitary brachytherapy boost. Am J Clin Oncol 1991;14:5-8.
20 Chen HY, Ma XM, Ye M, et al. Effectiveness and toxicities of intensity-modulated radiotherapy for patients with locally recurrent nasopharyngeal carcinoma. PLoS One 2013;8:e73918.

${ }^{21}$ Chan JKC, Bray F, McCarron P, et al. Nasopharyngeal carcinoma. In: Barnes L, International Academy of Pathology, World Health Organization, International Agency for Research on Cancer (editors). Pathology and genetics of head and neck tumours. Lyon: IARC Press; 2005. p. 85.

Received: February 13, 2016 - Accepted: July 28, 2016

Address for correspondence: Konstantinos Kourelis, Department of Otorhinolaryngology, Children's General Hospital "Karamandaneio", Erythrou Stavrou 40 st., 26331 Patras, Greece. Tel. +30 2610635204.

Fax +30 2610220511. E-mail: concourel@ hotmail.com 